\title{
Depuración del personal docente en la zona republicana durante la guerra civil
}

\author{
Rosalia Crego Navarro *
}

El presente trabajo de investigación trata de poner de relieve un hecho -el de la depuración republicana del personal docente ocurrido durante la guerra civil- que ha sido escasamente estudiado y por ello poco conocido, pero que es fácilmente explicable si se tiene en cuenta, como elemento básico, la radicalidad y absoluta contraposición de posturas ideológicas de los dos bandos enfrentados.

La primera consideración en relación con ella es que fue tanto más dura cuanto más elevado era el nivel social y profesional del depurado. (Catedráticos de Universidad, profesores numerarios de E. Normales o inspectores de Primera Enseñanza...), y tanto más paradójica cuanto que se aplicó también a personalidades politicas o intelectuales destacados, de reconocido republicanismo.

A continuación se destacará que fue una modalidad de represión política que se produjo en la zona republicana y en la nacionalista durante la guerra civil. Mucho se ha venido hablando durante años de la represión franquista, de tal modo, que siempre que se menciona la idea de represión se identifica con el régimen de Franco. También existió en la zona republicana.

Otra nota a tener en cuenta, en relación con lo anterior, es que la represión o depuración franquista fue más extensa en relación con los maestros y tuvo más repercusiones negativas, pero también en la repu-

* Asesora de Formación del Profesorado. CEP. Madrid - Norte. 
blicana fue lo suficientemente numerosa y significativa como para poner en peligro la innovadora reforma de la Escuela anhelada por la II República.

Sin embargo, en este artículo no se va a realizar un estudio comparativo entre los dos bandos contendientes, sin perjuicio de que para lograr un mayor rigor informativo en relación con el sector al que se refiere e! trabajo, se aporten datos estadísticos que cuantifiquen el alcance de la actuación depuradora.

A partir de las fuentes documentales consultadas - Gaceta de la República, diferentes periódicos y revistas profesionales de la época e incluso algún testimonio personal— resalta, por último, que dentro de una línea de depuración asumida por todos los Gabinetes ministeriales de Instrucción Pública, fue diferente, sin embargo, su actitud a la hora de ponerla en práctica y en las consecuencias de la misma.

\section{AMBIENTE DE CONFRONTACIÓN POLITICO-SOCIAL}

Durante los tres años que duró la guerra civil, y en línea coherente con la radicalidad ideológica que se produjo en ambos bandos, tuvo lugar una depuración que se justificó en este caso por razones de necesidad y en la idea de comprobar la fidelidad hacia el Gobierno de la República. Ya en el último bienio (1934-1936) y en los primeros meses del Gobierno del Frente Popular se habian manifestado durísimos enfrentamientos entre diferentes sectores sociales, asi como fuertes polémicas surgidas en los medios de comunicación. En los periódicos El Sol y El Debate se fue creando un estado de opinión en este sentido, y especialmente se pedía la depuración del profesorado de uno y otro bando.

Cuando se produjo la Revolución de octubre de 1934, comentando los sucesos de Asturias, El Debate de 31 de octubre decía:

«Los centros escolares, convertidos en centros de propaganda revolucionaria. Los maestros complicados en el movimiento forman verdadera legión... Se impone con urgencia y energía una labor depuradora del Magistero".

Luis Ortiz Muñoz, enviado especial para informar de aquellos sucesos, manifestaba en dicho periódico: 
Depuración del personal docente en la zona republicana durante ...

"Lo verdaderamente grave es que la preparación revolucionaria se ha hecho en gran parte en la escuela.

Alli ha ido a nutrirse de ideología marxista la población infantil de pueblos enteros... Sin que "pusieran coto los Gobiernos laicos y masónicos...". En el movimiento sedicioso está complicada una verdadera legión de maestros socialistas y comunistas... Lo que ahora importa es que una acción de Gobierno "depure la clase del Magisterio", obligándola, ante todo, a salir de sus Sindicatos socialistas..., desde la cual ha venido haciendo la labor criminal execrable: la corrupción de los niños..." '.

A través de $E /$ Sol las izquierdas desmienten estas y otras afirmaciones como las que hace Gil Robles sobre el tema de los numerosos profesores marxistas. Se las califica de evidentes exageraciones, pues tanto los profesores como la mayoría de maestros son "católicos practicantes", aunque hubiese minorias que simpatizasen con el "Fascio o con la hoz".

Por consiguiente, durante la guerra, con más razón, se fue creando un ambiente de represalia hacia aquellas personas cuya postura no estaba claramente del lado republicano.

La depuración se inscribe, pues, dentro del ámbito general de la guerra, en el que se toman medidas extremadamente radicales contra el enemigo al que se considera como "absolutamente perverso", y al que además se califica de forma virulenta de ufaccioso y enemigo de la República". A propósito de esta dureza, escribió Azaña en sus Memorias políticas y de guerra:

“En el territorio ocupado por los nacionalistas fusilaban a los fracmasones, a los profesores de Universidad y a los maestros de escuela tildados de izquierdismo, a una docena de generales que se habian negado a secundar el Alzamiento, a los diputados y exdiputados republicanos y socialistas, alcaldes y gobernadores, y a una cantidad difícilmente numerable de personas desconocidas; en el territorio dependiente del Gobierno de la República caian frailes, curas, patronos, militares sospechosos de fascismo, politicos de significación derechista..." 2 .

\footnotetext{
1 Periódicos: El Debate, 8-11-1934 y El Sol de 12-11-1935.

Luis Ortiz fue con el régimen de Franco, director del IB "Ramiro de Maeztu" antes Instituto-Escuela promovido por la ILE.

2 Azaña, M., Memorias políticas y de guerra, 2 vols. Barcelona, E. Grijalbo, 1978.
} 


\section{DISTINTAS MODALIDADES DE SANCIÓN}

La depuración, que como hemos dicho, fue un tipo de represión motivada por la guerra, se extendió a todos los funcionarios del Estado, incluido el personal administrativo y subalterno, así como a los funcionarios municipales y a todos los trabajadores relacionados o adscritos con instituciones u organismo oficiales (personal de los Ministerios, Ayuntamientos, jueces, polícia municipal...).

En este trabajo se va a estudiar la que se aplicó al personal docente de los diferentes cuerpos de profesores. Se realizó desde el propio Ministerio ya que sólo el Estado tenía capacidad para hacerlo, pues se trataba de funcionarios del mismo. No obstante, son los medios de comunicación, la prensa especializada o los periódicos de los sindicatos los que con mayor insistencia exigen este tipo de sanciones. El Magisterio Español (ME), incautado a sus dueños y convertido durante la guerra en órgano de FETE comenta en sucesivos ejemplares:

“España vibra en afán de regeneración, le interesa la depuración de todos sus organismos e instituciones..." ${ }^{3}$.

Este hecho negativo se encuadra dentro de una actitud, en el fondo beneficiosa, pues según la propaganda oficial iba a permitir llevar a cabo la auténtica reforma de la escuela que no se realizó durante el primer bienio republicano, como se afirmó anteriormente. Están muy claras, en este sentido, las siguientes palabras de esta editorial de la revista:

"Los enemigos de esta España pujante y gloriosa nos han puesto, sin quererlo, en el camino de las más rápidas soluciones... (...). Pues la ESCUELA ESPAÑOLA necesita, ante todo y sobre todo, maestros que alentados por un espíritu de independencia, graben en su personalidad, de modo perenne, el sello de los más firmes postulados de la Escuela

3 "Articulo Editorial». Magisterio Español (ME), de 25-8-1936. Fue incautado a sus dueños y convertido en órgano de propaganda del propio MIP cuando éste, estuvo dirigido por comunistas. César García Lombardia, era secretario general del FETE al producirse el alzamiento y fue nombrado director general de Primera Enseñanza. En su portada apareció en grandes caracteres: "El Magisterio Español ha dejado de ser órgano de la reacción. A partir de su incautación por FETE, ha pasado a ser el mejor defensor de los maestros y de la politica del Frente Popular». 
Nueva y Unificada, que es la única institución educadora capaz de formar una Humanidad redimida y salvada de tan atávicas concepciones como la han amordazado".

También se exige de los docentes una postura clara y terminante para situarse con "gallardia y sinceridad" a la izquierda o a la derecha. Los neutrales no pueden admitirse. Su actitud sólo serviria para empañar el medio en que se debaten la "libertad y la tiranía" ".

A través de la Gaceta de la República se fue dando forma legal a este tipo de actuaciones, si bien es fácil suponer que no siempre hubo razones suficientes para tomar medidas tan drásticas.

En un primer momento cuando el poder del Gobierno casi habia desaparecido todas las iniciativas de signo represor se toman por los diferentes "comités populares". Hecho que reconoce Dolores Ibarruri cuando en un mítin afirmó que el poder estaba en estos momentos donde "debía estar", es decir, en el pueblo ${ }^{5}$.

En relación con la depuración docente, la iniciativa partió de las propias Asociaciones de enseñantes que eligieron comisiones con esta finalidad.

Fueron estas comisiones las que reclamaban con insistencia a las autoridades ministeriales se procediera contra los enemigos de la República. Apoyan esta idea las palabras de la aludida revista de los maestros cuando sugiere: "Los señores del MIP y el director general de Primera Enseñanza tienen la obligación de depurar tanto a los maestros como inspectores y profesores de $E$. Normal. Es necesario que antes de comenzar el curso, hable la Gaceta" 6 .

Para llevar a cabo la depuración se aplicaron una variada gama de sanciones:

- Separación definitiva que suponía el cese con pérdida de todos los derechos (4.575).

- Jubilación forzosa (477).

- Traslado forzoso (629).

- Quedar a disposición gubernativa (84).

\footnotetext{
4 "Los maestros neutrales", Magisterio Español, núm. 6.641, de 25-8-1936.

${ }^{5}$ BOLLoten, B., La revolución española, sus origenes. La izquierda y la lucha por el poder durante la guerra civil, (1936-1939). Ed. Grijalbo. Edición nueva.

"Labor depuradora de la República". Magisterio Español. 29-8-1936, pág. 250.
} 
Como es fácil suponer la más grave y la más numerosa, fue la primera modalidad. Hubo algunos casos de cambios, de sanciones o de rehabilitación total si intervenian valedores del campo de los sindicatos que certificaban la adhesión al Régimen del depurado, por lo cual se levantaba, o cambiaba dicha sanción ${ }^{7}$.

Para la aplicación de esta sanción se utilizaron distintas fórmulas, las más frecuentes fue apelar al Decreto de Presidencia del Consejo de Ministros (27-9-36) que autorizaba al MIP a tomar cualquier medida contra docentes "no afectos" o bien tras un pequeño preámbulo en el que se afirma que: "La inspección........ ha comunicado........ Este ministerio de acuerdo con la propuesta formulada ha tenido a bien disponer que $\mathrm{D} /$ D. ${ }^{a}$......... cese en el escalafón, con pérdida de todos los derechos". Normalmente estaba firmado por el subsecretario. En cuanto a las otras sanciones se apela igualmente al anterior Decreto de la Presidencia para continuar con........ «Este Ministerio ha dispuesto......... El traslado, la jubilación forzosa o pasar a disponible gubernativo.

En el caso de cambio de sanción el texto utilizado fue: "Vistas las propuestas que conjuntamente formulan, el Consejo Provincial........, con el acuerdo favorable de la Dirección Privincial........ Este Ministerio ha resuelto dejar $\sin$ efecto........".

En otro plano, pero con fines idénticos, se utilizó otro recurso legal que fue la aplicación del artículo 171 de la entonces vigente ley de IP conocidas como Ley Moyano del año 1857 que decía:

"Los profesores que no se presenten a servir sus cargos en el término que prescriban los reglamentos o permanezcan ausentes del punto de residencia sin la debida autorización, se entenderá que renuncian a sus destinos: si alegaren no haberse presentado por causa justa se formará expediente........".

Según la norma del citado artículo 171, se debía incoar un expediente, y si no había informes suficientemente exculpatorios se cesaba al interesado con pérdida de todos los derechos, se le aplicaban otras sanciones (jubilación forzosa, traslado forzoso, pérdida de parte del sueldo........) o se le rehabilitaba, si se estimaba por las Juntas Sancionadoras "que habia habido algún error", como se afirmó anteriormente.

${ }^{7}$ Gaceta de la República (GR), de 15-1-1937. "Se rehabilita a los maestros de Alcoy, Ascensión Lapesa y Manuel Calviño....... Teniendo en cuenta que el consejo local, organizaciones políticas y sindicales y comisión depuradora reconocen el error seguido........". 
Pese a que en el texto de la GR se habla de "expediente disciplinario" lo cierto es que no se han hallado documentos al respecto. Solamente se han recogido oficios de la Dirección General de Primera Enseñanza dirigidos a los presidentes de los Consejos Municipales comunicándoles que ciertos maestros han sido sancionados ${ }^{8}$. Es fácil suponer que la confusión de la guerra crease estas situaciones y bastara como se decía en la prensa:

\section{... "Que hablara la Gaceta"...}

La modalidad de declarar al profesorado incurso en el artículo 171 fue la segunda en importancia (aplicada a 701 docentes). Se iniciaba a partir de los informes que hacian los inspectores de $1 .^{\mathrm{a}} \circ 2 .^{\mathrm{a}}$ enseñanza sobre aquellos maestros o profesores que no se hallaban al frente de su plaza, pues se habian dado órdenes a todo el personal docente para que estuviera en sus destinos y si su plaza estaba en zona "facciosa" se pusieran a disposición de los organismos competentes... ${ }^{9}$.

Veamos el alcance de la depuración según las distintas modalidades aplicadas:

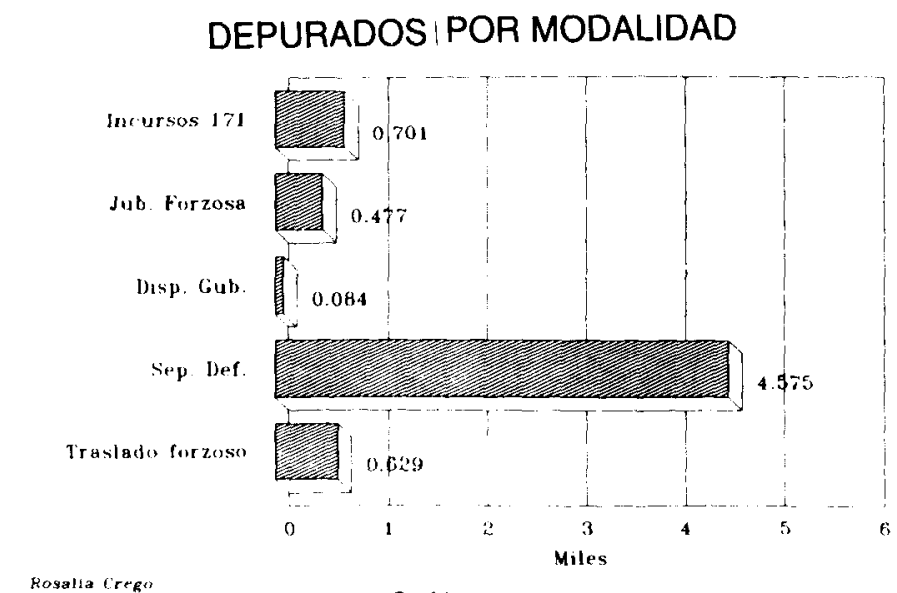

Gráf. 1.

${ }^{8}$ En el Archivo Municipal de Gandía se hallan documentos en los que la Dirección General de Primera Enseñanza comunica al presidente del consejo el nombre de los maestros sancionados y el tipo de sanción para que a su vez se lo comunique a los interesados. En este caso se trata de $\mathrm{M}^{\mathrm{a}}{ }^{\mathrm{G}}$ Gracia Cucart, José Faus Mascarell y Eduvigis Garcia, cesados acogiéndose al Decreto de la Presidencia del Consejo de Ministros de 27 de septiembre de 1936 y mediante orden publicada en la GR, de fecha 20-1-1937.

${ }_{9}^{9}$ La GR publica en diferentes Órdenes que los profesores se presenten ante las autoridades académicas con objeto de conocer la situación real de la enseñanza y el número de profesores con los que cuenta y son por tanto "afectos al régimen". 


\section{ACTUACION DE LOS DISTINTOS GABINETES MINISTERIALES}

A pesar de que las depuraciones fueron un hecho general durante la guerra, hay diferencias de matiz según las características de los diferentes Gabinetes Ministeriales porque eran muy distintas las ideologias que subyacian en los planteamientos de los mismos y que condicionaron su actuación: El primer ministro de IP era liberal republicano, el segundo militante del partido comunista y el último auténticamente libertario.

Durante el corto tiempo que va entre el 18 de julio al 5 de septiembre de 1936, siendo ministro Francisco Barnés, y pasado el estupor de los primeros días del alzamiento, comienzan a aparecer los ceses de aquellas personas que habían "destacado más en las derechas convervadoras": Directores de Colegios Públicos, e Institutos de Segunda Enseñanza, inspectores de Primera Enseñanza, profesores de Normal o Universidad... ${ }^{10}$. En este periodo parece deducirse que el ministro se vio presionado por los diferentes comités o las juntas especiales creadas al efecto y compuestos por representantes de los partidos del Frente Popular y de los sindicatos y cuyas directivas se orientaron inmediatamente a proponer la depuración. En esta línea también la Asociación de Doctores y Licenciados catedráticos de Instituto y los diferentes Consejos Escolares se ocuparon como primera medida de detectar qué profesores de Segunda Enseñanza o maestros no eran «afectos al régimen».

Del mismo modo se formó posteriormente una comisión, designada por la junta organizadora de la Enseñanza Profesional, que tenía la misión de depurar al personal docente, administrativo y subalterno de las Escuelas Elementales y Superiores del Trabajo, pues según la propia Gaceta, esta Comisión:

«... Toma una serie de medidas para que queden supensos de empleo y sueldo hasta que acrediten su adhesión al Gobierno y condenen, sin género alguno de reservas el movimiento sedicioso..." ".

${ }^{10}$ El 1 de agosto de 1936 se publicó un Decreto en la GR, por el que se consideraban vacantes todos los rectorados, direcciones y secretarias de todos los centros. El 31 de agosto de 1936. La GR publica el cese de muchos directores de escuelas.

"GR, de 15-10-1936. 
Depuración del personal docente en la zona republicana durante ...

Son varios los comentarios de la prensa profesional fomentando esta actitud represora e insistiendo en el gran número de docentes de "derechas con espiritu pedagógico arcaico y reaccionario", que "no sienten los anhelos de democracia y sentido social de la nueva escuela...".

De hecho hay una sección habitual dentro de la mencionada revista Magisterio Español que se llama Labor Depuradora de la República, cuya misión era brindarle al señor ministro la posibilidad de realizar esta "obra de saneamiento e higienización de todos los organismos..." ${ }^{12}$.

Ahora bien, a partir de septiembre de 1936 y por propia iniciativa del nuevo ministro Jesús Hernández, comenzó una depuración de la que se hace incluso propaganda; en este sentido hizo unas declaraciones a los pocos dias de su nombramiento en las que hablaba:

«... de depurar al personal docente... a todo el personal... es preciso depurar desde los organismos superiores de la cultura hasta la escuela primaria" ${ }^{13}$.

En otra ocasión e insistiendo en este alarde sobre el afán represor, el ministro hizo unas declaraciones en El Mundo Obrero, recogidas y publicadas por $A B C$ en las cuales dijo:

«... Hay además otro personal que es preciso depurar: me refiero al señorito fascista, al parásito empapelado de títulos académicos... He de depurar al cuerpo estudiantil en las Universidades y en los Institutos..." ${ }^{14}$.

Tal como lo manifestó lo hizo. Pocos dias más tarde, se publicó en la Gaceta un Decreto que disponía que quedaran en suspenso los derechos adquiridos por los alumnos, los cuales, tenian que demostrar ante un comité seleccionador presidido por un director-comisario e integrado por los sindicatos, su adhesión al Gobierno, "para evitar que los organismos oficiales sean focos de hostilidad y de conspiración contra la Repú-

${ }^{12}$ En la citada tantas veces revista Magisterio Español existió una sección fija titulada: "Labor depuradora de la República", y cuya misión era la de recordar a los responsables del MIP la necesidad de realizar una depuración exhaustiva.

${ }_{13}$ Declaraciones hechas a la revista Magisterio Español el 15-9-1936. También comentó cuales serian sus líneas generales de actuación.

${ }_{14}$ Declaraciones hechas por J. Hernández y recogidas por $A B C$ el 13-9-1936, págs. 11 y 12 . 
blica... y dando aplicación al principio que los enemigos de ésta no son acreedores de recibir enseñanza». Este comité tendrá en cuenta los antecedentes que proporcione la FUE que conocía muy bien que estudiantes eran de derechas o simpatizaban con ellas ${ }^{15}$.

Pocos dias más tarde se publicó un Decreto-ley firmado por Azaña a instancias del MIP por el cual se podian trasladar libremente a maestros, profesores de las diferentes Escuelas, catedráticos de Institutos y de Universidad sin respetar los derechos adquiridos ${ }^{16}$. Esta actitud se justifica por "necesidades de la guerra".

También mediante Decreto-ley se aplica el cese automático de todos los funcionarios sin excepción y para pedir el reingreso se debían rellenar unos impresos orientados a demostrar la adhesión absoluta a la "causa republicana", avalada por un partido político o sindicato ${ }^{17}$. Para que no haya dudas al respecto "se suspende el pago de haberes a todo el personal docente... en tanto no acrediten su lealtad al régimen».

Como acciones más llamativas y por la misma vía legislativa del Decreto, se cesó a todos los maestros de Navarra, Las Palmas y Tenerife, gran cantidad de catedráticos e inspectores e incluso jóvenes estudiantes perdieron sus becas por hacer declaraciones en favor de los rebeldes o contra los republicanos ${ }^{18}$.

En el último período de la guerra en que el MIP estuvo a cargo de Segundo Blanco, se continuó en la misma línea de depurar aquellos docentes que todavía no habian sido sancionados, y de los que se sospechaba su "no afección al régimen». No obstante, el número se reduce sensiblemente ya que hay menos personas que depurar. No obstante, existe un documento que evidencia muy claramente qué opinión tenía el propio ministro sobre esta cuestión. Se trata de una carta de fecha 23 de noviembre de 1938 en la que contesta al ministro de Justicia, Ramón González Peña sobre el tema planteado por éste de que los inspectores de Primera Enseñanza viven tranquilamente en Barcelona mientras «hay

15 Decreto de 19-9-1936, publicado en GR, núm. 264, de 20-9-1936.

16 Decreto de 22-9-1936, publicado en GR, n. ${ }^{\circ} 268$, de 24-9-1936.

17 Decreto de la Presidencia del Consejo de Ministros, del 27-9-1936, publicado en GR, 28-9-1936. Impresos a rellenar para solicitar el reingreso GR, de 30-9-1936.

${ }^{18}$ Sobre las fechas de los diferentes Decretos u órdenes depuradores, véanse en Anexo Documental. 
muchos pueblos donde se dá enseñanza particular (que estaba prohibida) e incluso por antiguas monjas y otros enemigos de la República...". Ante este hecho, que le produjo gran irritación al ministro de IP y éste extrañado, contesta preguntando que hicieron las juntas depuradoras para que en todo caso: "procederé con la más rigurosa energía contra quien sea..." ${ }^{19}$. Poco más tarde dio las órdenes oportunas obligando a los inspectores a residir en las zonas adscritas a su competencia. Con esta medida trató, en suma, de controlar que no estuvieran a cargo de las escuelas "desafectos al régimen» ${ }^{20}$.

También existen documentos sobre casos en que se rehabilitó a ciertos profesores o inspectores injustamente depurados por los comunistas a los que siempre tacharon de sectarios ${ }^{21}$.

El gráfico que se aporta a continuación confirma ampliamente cual fue la actuación de los diferentes Gabinetes Ministeriales en relación con la depuración.

\section{DEPURADOS POR GABINETE MINISTERIAL}

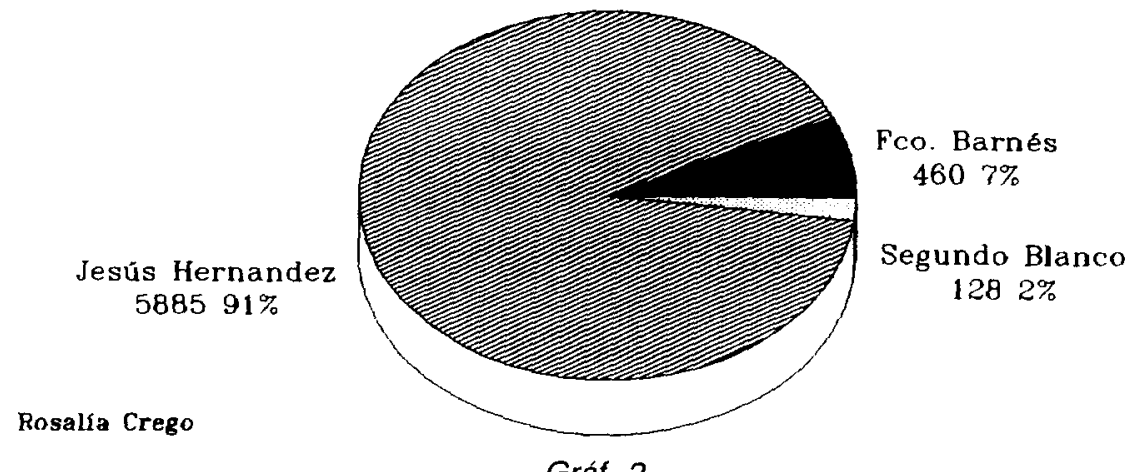

Gráf. 2.

${ }_{19}$ Carta dirigida a D. Ramón González Peña, el 23-11-1938. International Institunt vor Sociale Geschedenis, (I. ISSG), de Amsterdam. Caja 341, paquete 29, film 59.

20 Ordenes a los inspectores de Primera Enseñanza, obligándoles a visitar periódicamente los pueblos de la zona asignada e informar sobre todas las circunstancias. IISG de Amsterdam.

${ }^{21}$ Véase en el Anexo Documental, aquellos docentes que fueron sancionados y luego rehabilitados. También hay documentos en el archivo de Segundo Blanco en el IISG de Amsterdam sobre un inspector de Guadalajara, Luis Ortiz, que fue no sólo rehabilitado, sino nombrado inspector jefe. 


\section{POSTURAS POLÍTICAS CONTRAPUESTAS DE INTELECTUALES REPUBLICANOS}

Aquellos intelectuales "rigurosos" como les llama Marichal, que, comenzaron su quehacer profesional hacia el año 1914 estuvieron deliberadamente comprometidos con el poder político de la II República, o fueron directamente sus dirigentes. Para todos ellos, alcanzar el desarrollo social y cultural a través de la educación era el objetivo fundamental ${ }^{22}$.

Reconocido este punto de partida, sus posturas se fueron diversificando al compás de los acontecimientos políticos, bien porque se sintieran defraudados bien porque fracasaron en su empeño «atrapados» en "sus contradicciones de clase" e ignoraron a un "proletariado" que por circunstancias históricas se convirtió en dirigente político durante la guerra $^{23}$.

Iniciada ésta, la mayoría de aquellos intelectuales salió del país (algunos antes). Su actitud tampoco fue comprendida por estos "dirigentes proletarios", los cuales procedieron contra ellos, en especial si eran profesores y por tanto dependian administrativamente del Ministerio de I.P. A través de diferentes Decretos $u$ órdenes ministeriales se le aplicaron distintas modalidades de sanción de acuerdo al grado de rechazo que sintiera el ministro que estuviera a cargo del Gabinete. En este caso, casi todos fueron sancionados en el periodo comprendido entre el 5 de septiembre de 1936 a marzo de 1938. Estaba al frente del MIP: Jesús Hernández.

Una modalidad aplicada a los intelectuales fue la del artículo 171 que no era propiamente sanción, ya que tenía un carácter general y pretendía que el profesorado no se ausentara de su trabajo sin causa justificada; se utilizó sin embargo, durante la guerra habitualmente como medida represora contra los profesores especialmente de Universidad que habian «huido" al extranjero a causa de la guerra y en cuyos países

22 Vid: MARichal, J., "La vocación de Manuel Azaña", Cuadernos para el Diálogo, Madrid, 1971.

${ }^{23}$ Barreiro, H., Lorenzo Luzuriaga y la renovación pedagógica en España. (18891936). Coruña, Edición do Castro, 1989. 
Depuración del personal docente en la zona republicana durante ...

dependían en cierta medida del sueido que cobraban del MIP. No tiene sentido aplicarles dicha ley si no era para poner en evidencia una conducta que desaprobaba el Gobierno. Apoyan lo expresado anteriormente la Orden Ministerial de 2 de diciembre de 1937 que sirvió para declarar incursos en el citado artículo a personalidades tales como ${ }^{24}$ :

- Niceto Alcalá Zamora.

- Américo Castro.

- Claudio Sánchez Albornoz.

- Ramón Prieto Bancés.

- José Ortega y Gasset.

La citada orden en su exposición de motivos dice: "Un grupo de profesores universitarios, manifestando una evidente falta de solidaridad con el pueblo español que lucha con abnegación heroica en defensa de las libertades nacionales, ha faltado abiertamente al cumplimiento de sus deberes más elementales desoyendo el llamamiento del Gobierno y permitiendo con su abstención que sus enseñanzas pudieran quedar desatendidas, cosa que sólo se ha podido evitar por el celo con que otros profesores, con un sentido más elevado de sus obligaciones profesionales, se han dispuesto suplir sus ausencias» ${ }^{25}$.

Por el contenido del reseñado texto se puede deducir el deseo de los dirigentes del MIP de poner en evidencia la falta de solidaridad de dichos enseñantes.

A otros se les aplicaron sanciones más graves. La fórmula fue: "En uso de las atribuciones conferidas por el Decreto de la Presidencia del Consejo de Ministros de 27 de septiembre de 1936... Este Ministerio ha acordado, la separación definitiva del servicio con pérdida de todos los derechos profesionales...".

${ }^{24}$ El MIP previamente por Orden de 28-8-1937, hace un llamamiento a todos los catedráticos, profesores, auxiliares y encargados de curso de todas las Universidades, residentes en territorio leal o en el extranjero para que se presenten en la Secretaria de la Universidad de Valencia ante los decanos respectivos.

${ }^{25}$ Orden Ministerial de 2-12-1937, GR del 4-12-1937. 
Los más destacados fueron:

Lorenzo Luzuriaga: Introductor de la E. Nueva. Pedagogo de gran prestigio. Elaboró el anteproyecto sobre el que se basó el programa educativo del primer bienio republicano: Sep. Def. (OM, 30-9-1937, GR, 210-1937) ${ }^{26}$.

María de Maeztu: Directora del Inst. Escuela que lleva el nombre de su hermano y directora del centro "Residencia de Estudiantes-Señoritas". Sep. Def. (GR, 28-7-1937).

Domingo Barnés Salina: Ministro y subsecretario de IP, (12-9-1932 a 16-12-1933. Sep. Def. GR, 28-7-1937).

Gregorio Marañón: Conocido intelectual y médico de gran prestigio. Catedrático de Universidad. Sep. Def. GR, (22-11-1937).

José Pareja Yébenes: Ministro de IP, (16-12-1933 a 3-3-1934). Catedrático de la Universidad de Granada. Sep. Def. GR, (22-11-1937).

Contra estos y otros españoles republicanos se produjo una animadversión que comentó Azaña en su obra Memorias Políticas y de Guerra, señalando como antes y durante la guerra fueron numerosos los intelectuales y políticos que solicitaron excedencias, traslados, o misiones diplomáticas en el exterior o se dedicaron a "tournés" por universidades europeas o americanas. Contra ellos se produjo un cierto recelo que al prolongarse la guerra se transformó en auténtica aversión.

Por el contrario se exageran las alabanzas y elogios en torno a los intelectuales que estuvieron al lado de "los heroicos soldados" compartiendo una situación tan dura y llena de violencias.

${ }^{26}$ En el caso de Lorenzo Luzuriaga, su hija Isabel a la que entrevisté no conocia tal circunstancia. En el libro titulado: Lorenzo Luzuriaga y la renovación educativa en España, (1889-1936) de Herminio Berreiro Rodríguez. Edición do Castro. Coruña 1989, recoge el autor que fue sancionado pese a que habia sido destinado por el Ministerio de Estado a Gran Bretaña (25-9-1936). Este nuevo destino cuya finalidad era salir de España, no fue evidentemente bien acogido por el MIP que le cesó con pérdida de todos los derechos. Hecho que el citado autor desconoce. Importa destacar que recoge un documento singular: Una carta de L. L. a Bernardo Giner de los Ríos, ministro interino del Ministerio de Estado, agradeciéndole, que le facilitara la salida de España, ya que estaba amenazado por el "Soviet que se creó en aquel Ministerio". (Se refiere sin duda al MIP). 
Este es el mensaje que en torno a la venida a España de León Felipe y de Luis Cernuda se intenta reflejar en el El Mono Azul:

"Vuelve León Felipe a España, con ello dá dignísima réplica a los que de sí, dicen, saliendo de España...".

"Luis Cernuda en Madrid. Ha vuelto de París. Viene cuando algunos se van" ${ }^{27}$.

En el mismo sentido está la consideración y afecto que se dirigió hacia otros intelectuales que estuvieron presente en la lucha como es el caso de Antonio Machado, que permaneció en España hasta el último momento e hizo frecuentes manifestaciones de adhesión a favor de la "causa republicana" ya que era la del pueblo trabajador, del que siempre se sintió cerca.

Dentro de la línea de rechazo podemos situar el cese de D. Miguel de Unamuno como Rector Vitalicio de la Universidad de Salamanca y como presidente del Consejo Superior de Cultura, al que incluso se le quita su nombre de diferentes Centros de Primaria o Segunda Enseñanza que lo llevaban en Madrid y Bilbao, por otro de persona claramente "afecta" a la ideologia de las izquierdas y ello, por unas declaraciones que hizo sobre la crueldad de "los bárbaros milicianos". Por el contrario se nombra a Pablo Picasso, director del Museo del Prado, aunque estaba fuera de España, porque tanto en sus manifestaciones como en su obra se mostró partidario de la causa republicana ${ }^{28}$.

${ }^{27}$ El Mono Azul, núm. 6, de 1-10-1936, pág. 48. En el caso de Gregorio Marañón se publican artículos de Margarita Nelken en Mundo Obrero, llamándole en tono despectivo "Doctor Astracán".

${ }^{28}$ GR, de 27-10-1936. Decreto... "que deja nulo y sin efecto el nombramiento de D. Miguel de Unamuno, como rector Vitalicio de la Universidad de Salamanca...". También existen artículos comentando las declaraciones de Unamuno en la citada revista Magisterio Español y en el periódico Mundo Obrero. Existe sobre este hecho un artículo de Ylya Ehremburg, corresponsal del Pravda recogido en el Mono Azul, núm. 4, de 17-9-1936, pág. 25 , en el que justifica la acción de los "Bárbaros milicianos", ya que su escasa cultura, tiene su causa en que las instituciones monárquicas no se preocuparon de su educación. En el nombramiento de Pablo Picasso se publicó en la GR, de 20-10-1936. Nunca tomó posesión de su cargo. 
Sobre el apoyo al Gobierno de la República durante la guerra de intelectuales españoles, aparte de los conocidos literatos y escritores en aquellos momentos muy jóvenes, que componian la Alianza de Intelectuales (Alberti, Altolaguirre, Prados, Bergamín...), pueden resultar altamente significativos dos escritos “inéditos" de Antonio Machado que aclaran de qué modo se hallaba identificado el gran poeta castellano con la esencia de la República. De estos textos, que se pueden consultar integros en el anexo documental, elegimos algunos párrafos del primero de ellos, que hablan del reconocimiento del autor hacia los gobernantes republicanos.

«... Unos cuantos hombres honrados, que llegaban al poder sin haberlo deseado... pero obedientes a la voluntad progresiva de la nación... Para esos hombres eran sagradas las más justas y legitimas aspiraciones del pueblo... Y estos hombres nada revolucionarios, llenos de respeto, mesura y tolerancia, ni atropellaron ningún derecho (...).

“... Los militares rebeldes, volvieron contra el pueblo todas las armas que el pueblo habia puesto en sus manos para defender a la nación, y como no tenían brazos voluntarios para empuñarlas, los compraron al hambre africana... Pero la fortaleza de la tercera República sigue en pie. Hoy la defiende el pueblo contra los traidores de dentro y los invasores de fuera, porque la República que comenzó siendo una noble experiencia española, es hoy España misma. $Y$ es el nombre de España, sin adjetivos, el que debemos destacar en esta 14 de abril de $1937 "$ ".

En el segundo escrito, esta vez dirigido a Tomás Navarro, Tomás con motivo de la reinauguración de la Casa de Cultura en Valencia, apoya la gestión de Jesús Hernández en estos términos:

“... “El Ministerio de Instrucción Pública digámoslo sin ánimo de adular a nadie, sino como tributo obligado a la verdad más obvia aparece en España por primera vez a la altura de su misión" en la estructura nueva que ha dado a la Casa de los Sabios ha prescindido de cuanto pudo haber en ella de solemne y decorativo, la ha convertido en un hogar para los espíritus, en un taller para las más nobles faenas de la inteligencia, consagrando generosamente a satisfacer de un modo más o menos directo la sed de cultura que hoy siente nuestro pueblo..." ${ }^{29}$.

${ }^{29}$ Véanse en M.E. 16 abril 1937 y 24 mayo 1937 
Como hemos podido comprobar está muy clara la postura comprometida y coherente del poeta que tan admirablemente cantó a Castilla, en relación con la causa del Gobierno Republicano del Frente Popular y particularmente con el Ministerio de Instrucción Pública. El hecho de permanecer en España durante la guerra supuso un gran gesto de honradez, tanto más apreciable cuando le hubiera sido sumamente fácil, por su prestigio, conseguir un puesto de profesor en el extranjero ya que fue amigo personal de Antonio Ballesteros Usano, inspector General de Colonias y presidente de la Asociación de Amigos de la Unión Soviética. Fue casi la excepción, ya que para la mayoria de los intelectuales fueron más fuertes el miedo, el instinto de conservación y quien sabe si el componente de clase...

\section{ALCANCE DE LA DEPURACIÓN REPUBLICANA Y COMENTARIO DE DATOS}

Para la elaboración de los datos que se van a exponer a continuación se ha utilizado un proceso informático - Base de datos Lotus- en la que se ha incluido una relación nominal del personal docente depurado, obtenida a su vez de la Gaceta de la República - periodo del 20 de julio de 1936 a 31 de diciembre de 1938-. En dicha relación, que por motivo de espacio no se incluye como Anexo Documental pues está formada por 6.473 sancionados, se recogen distintos datos con los que se han realizado diferentes gráficos:

- Fecha de la sanción (Gráfico núm. 2).

- Cargo del interesado (Gráfico núm. 3).

- Provincias de destino (Gráfico núm. 7).

- Modalidad de sanción (Gráfico núm. 1).

Respecto a los gráficos de porcentajes se han utilizado además fuentes bibliográficas y Anuarios del MIP de los años 1933 o 1935. Gráficos núms. $4,5,6,8$ y 9 . 
DATOS ESTADÍSTICOS EN RELACIÓN A PERSONAL DOCENTE DEPURADO

\begin{tabular}{|c|c|c|c|}
\hline & $\begin{array}{c}\text { TOTALES } \\
\text { SANCIONADOS }\end{array}$ & $\begin{array}{c}\text { PERSONAL } \\
\text { EN ACTIVO } \\
\text { EN } 1935\end{array}$ & PORCENTANE \\
\hline 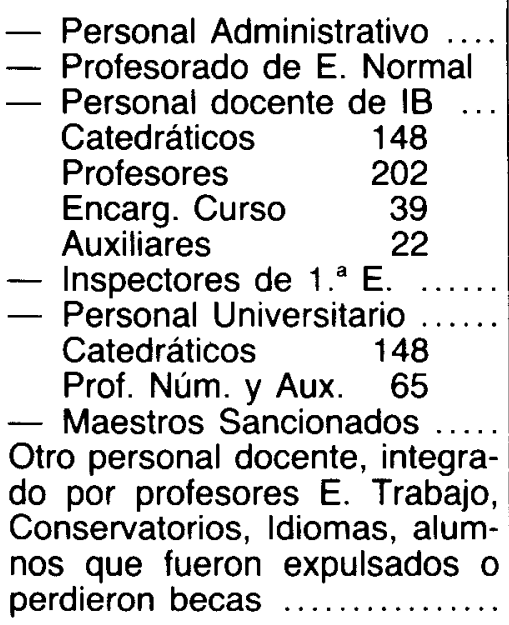 & $\begin{array}{r}160 \\
213 \\
5.281 \\
173\end{array}$ & $\begin{array}{r}377 \\
1.366 \\
51.593\end{array}$ & $\begin{array}{l}42,44 \\
15,59 \\
\\
10,23\end{array}$ \\
\hline Total depurados & 6.473 & & \\
\hline
\end{tabular}

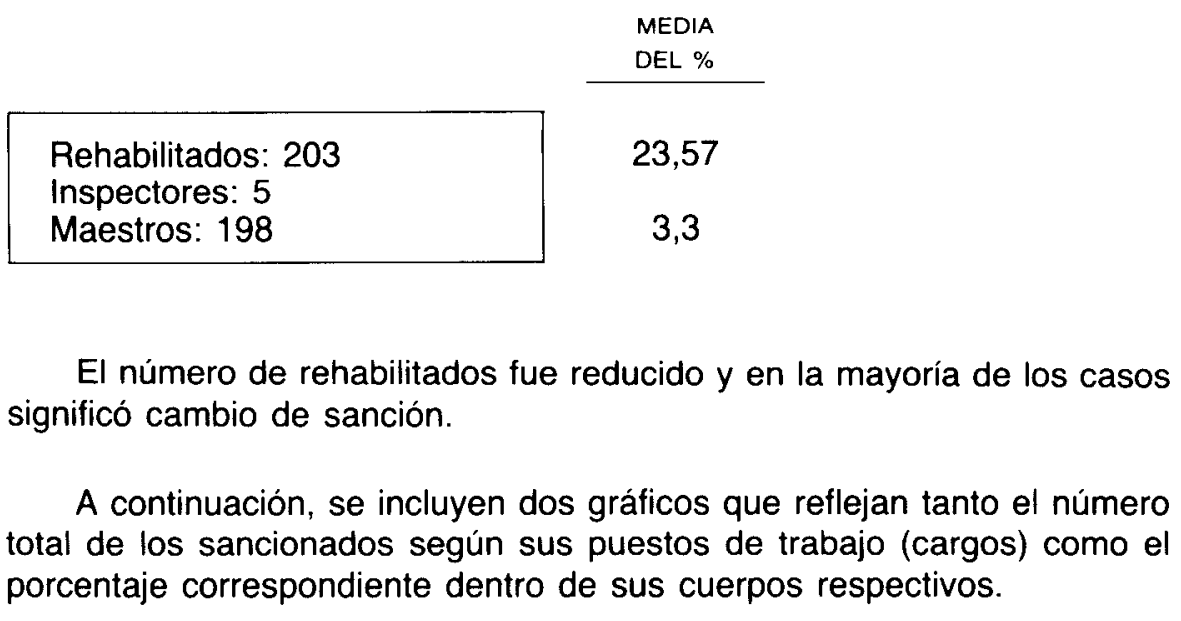


Depuración del personal docente en la zona republicana durante ...

\section{DEPURADOS POR CARGO}

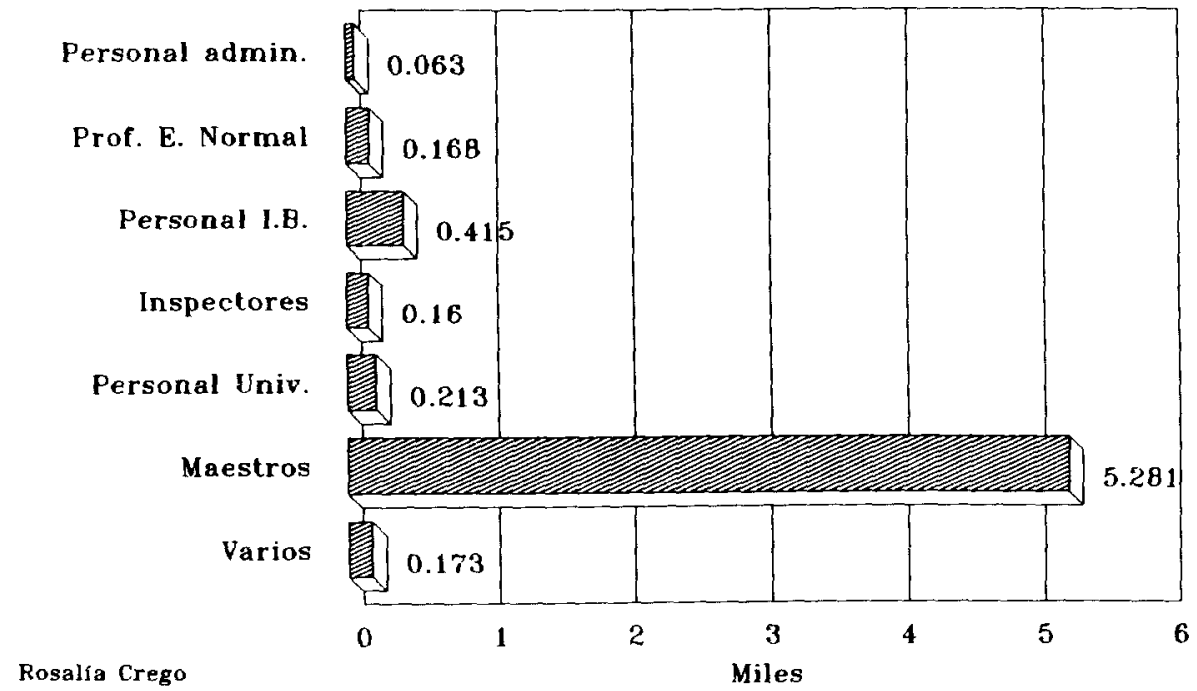

Grát. 3.

Prof. E. Normal

Personal I.B.

Inspectores

Personal Univ.

Maestros

Rosalía Crego

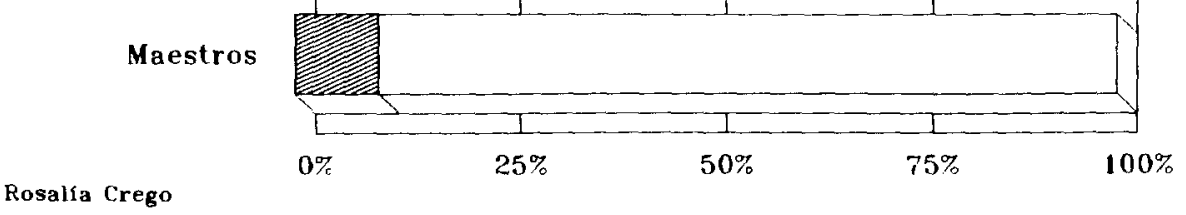

Gráf. 4. 
Como hemos observado en los gráficos pese a que el número de maestros depurados es muy grande, su porcentaje es el más pequeño, relativamente.

A continuación, dentro de lo posible, se va a escoger una muestra de las 15 provincias señaladas en el mapa y se va a tratar de dar un porcentaje más ajustado a la realidad «poniendo en relación los datos de los distintos docentes depurados, con el personal en activo tomando como referencia los datos del Anuario estadístico del año más próximo a la guerra, 1935".

Conviene advertir que en el trabajo está centrado fundamentalmente en la escuela y en aquellos organismos relacionados directamente con ella: Inspección del Magisterio y Escuelas Normales, aunque se amplíe el estudio a la Universidad o Institutos.

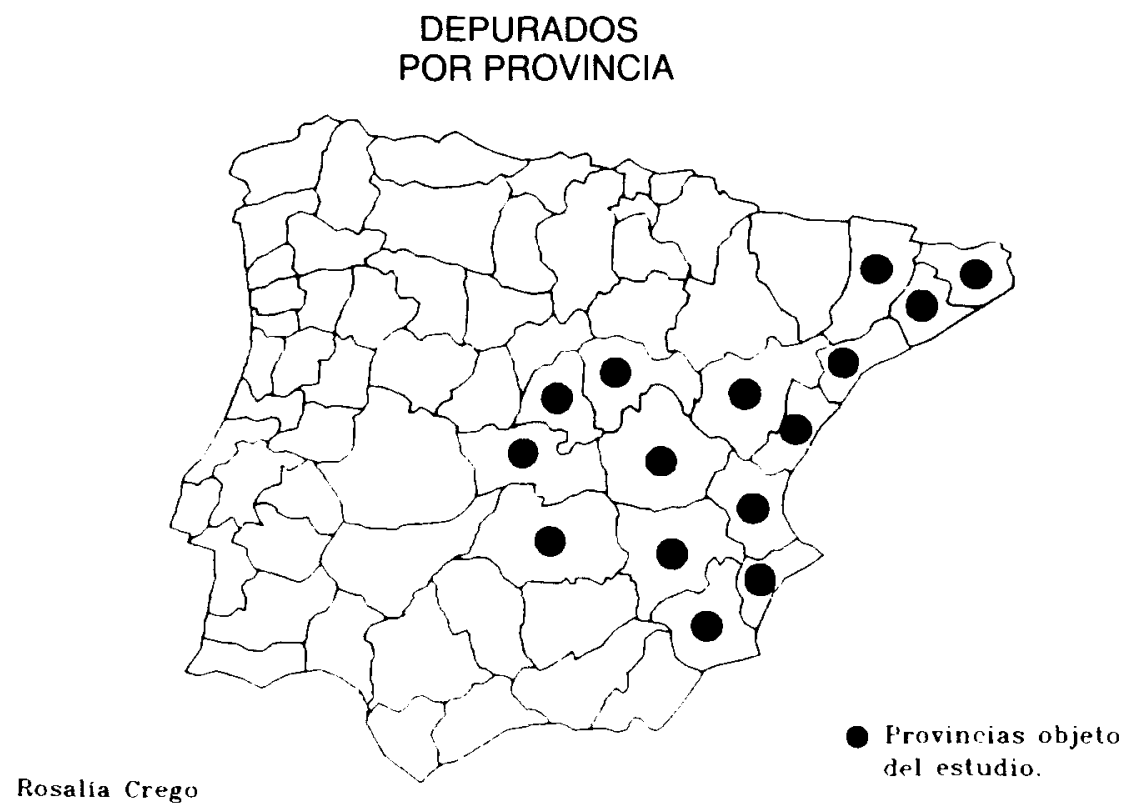

Como se observó anteriormente en la gráfica núm. 4 existió un elevado porcentaje de inspectores de Primera Enseñanza depurados.

En una ocasión la revista $M$. $E$. citada se refiere concretamente al Cuerpo de Inspectores que "tal como hoy está integrado no nos sirve... Ni 
un momento más, permanecerán en el Ministerio de Instrucción Pública elementos reaccionarios...». Está muy claro que son el primer cuerpo a depurar. En la misma línea se encontraban los catedráticos de Universidad de IB y de E. Normales que eran consideradas las "élites" de la docencia ${ }^{30}$.

En cuanto a la depuración del Cuerpo de Inspectores de Primera Enseñanza, se ha observado que el número de inspectores depurados (160), en relación con la totalidad de los mismos (que según fuentes estadísticas del MIP para 1933 dan una cifra de 377) era elevada, $(42,44 \%)$, no obstante este dato no es del todo correcto, porque hay muchas provincias que estuvieron desde casi el inicio de la guerra en manos de los nacionalistas y que al no tener influencia sobre ellas, sólo aquellos inspectores, derechistas destacados, les incluyen entre los depurados. Por ello hemos elegido quince provincias que permanecieron del lado republicano para comprobar que el grado de depuración de éstos, fue el más elevado de todo el personal docente, seguido de los profesores de E. Normal, de los Catedráticos de Universidad o Segunda Enseñanza, pero de cuyos colectivos no es posible hacer el porcentaje con el mismo rigor por carecer de datos exactos. En cuanto a los inspectores tomamos dicha muestra y observemos lo que ocurre:

so «Maestros, profesores, inspectores». M. E., 25-9-1936, pág. 235. 
ROSALIA CREGO NAVARRO

\begin{tabular}{|c|c|c|}
\hline PROVINCIAS & $\begin{array}{l}\text { INSPECTORES } \\
\text { NOMBRADOS * }\end{array}$ & $\begin{array}{l}\text { INSPECTORES } \\
\text { DEPURADOS * }\end{array}$ \\
\hline Albacete .... & 4 & 1 \\
\hline Alicante .... & 6 & 6 \\
\hline Barcelona...... & 11 & 7 \\
\hline Castellón & 4 & 0 \\
\hline Ciudad Real ........ & 3 & 0 \\
\hline Cuenca ..... & 5 & 2 \\
\hline Gerona & 4 & 2 \\
\hline Guadalajara & 6 & $6 * 1$ Reh. \\
\hline Lérida ........ & 7 & 3 \\
\hline Madrid & 13 & 8 \\
\hline Murcia & 7 & 6 \\
\hline Tarragona & 5 & 5 \\
\hline Teruel .... & 5 & 4 \\
\hline Toledo ... & 5 & 3 \\
\hline Valencia & 10 & 5 \\
\hline Total & 95 & 55 \\
\hline
\end{tabular}

- Datos tomados de LLOPIS, Rodolfo, La revolución en la escuela, dos años en la Dirección General de Primera Enseñanza. Madrid, Aguilar Editor, 1933, págs. 168 a 177, y de la Gaceta de la República, en las fechas correspondientes en las que se publica la depuración.

Porcentaje de depuración: 59,09\% frente al $42 \%$ anterior. En la gráfica se representan estos datos. 
DEPURADOS

POR PROVINCIA

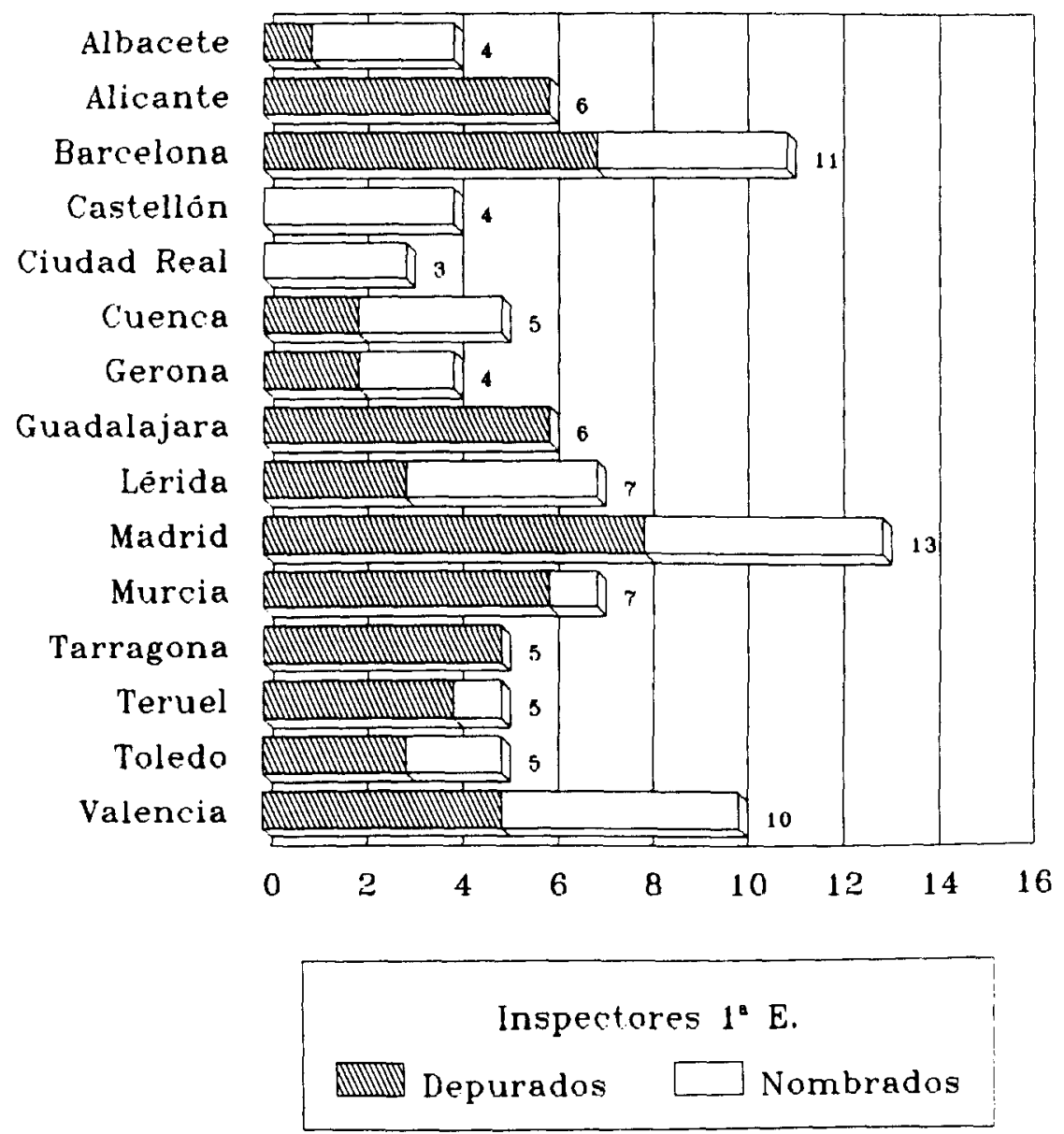

Rosalfa Crego

Gráf. 5. 
En cuanto a los profesores de "Escuelas Normales" también se observa que fueron especialmente depurados los profesores numerarios. Los datos que se poseen son los siguientes: había un total de 532 profesores/as en las 52 Escuelas Normales del país. El porcentaje de depuración fue:

Profesores Numerarios: 532

Profesores Depurados: 168

$$
\text { Porcentaje: } \quad 31,57 \%
$$

En este caso se desconocen el número de profesores de cada Escuela Normal, por lo cual no se ha podido proceder a un cálculo más exacto por provincias.

LOS MAESTROS DEPURADOS DE LA MUESTRA DE LAS PROVINCIAS EN RELACIONN CON LOS TOTALES ARROJAN LAS SIGUIENTES CIFRAS

\begin{tabular}{|c|c|c|}
\hline PROVINCIAS & DEPURADOS & $\begin{array}{l}\text { MAESTROS } \\
\text { EN ACTIVO }\end{array}$ \\
\hline 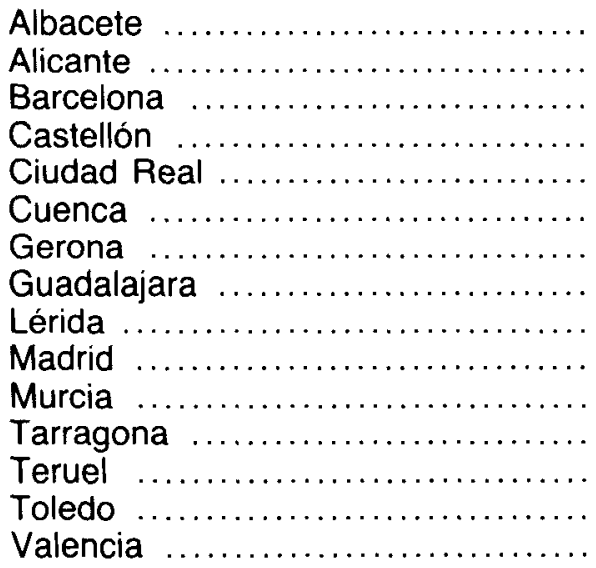 & $\begin{array}{r}125 \\
148 \\
159 \\
291 \\
57 \\
123 \\
65 \\
211 \\
115 \\
270 \\
168 \\
128 \\
40 \\
275 \\
344\end{array}$ & $\begin{array}{r}609 \\
1.011 \\
1.072 \\
737 \\
594 \\
688 \\
766 \\
713 \\
1.072 \\
2.010 \\
1.072 \\
773 \\
732 \\
804 \\
1.274\end{array}$ \\
\hline Total depurados ............ & 2.519 & 15.471 \\
\hline
\end{tabular}

Porcentaje de depuración: $16,28 \%$. Como se observa es un poco más alto que el porcentaje global, pero es más bajo que el de los otros cuerpos de docentes.

(En la gráfica de elaboración propia, como las anteriores y utilizando las mismas fuentes se visualiza mejor que el porcentaje fue escaso).

* Anuario estadístico de 1935. 
DEPURADOS

POR PROVINCIA

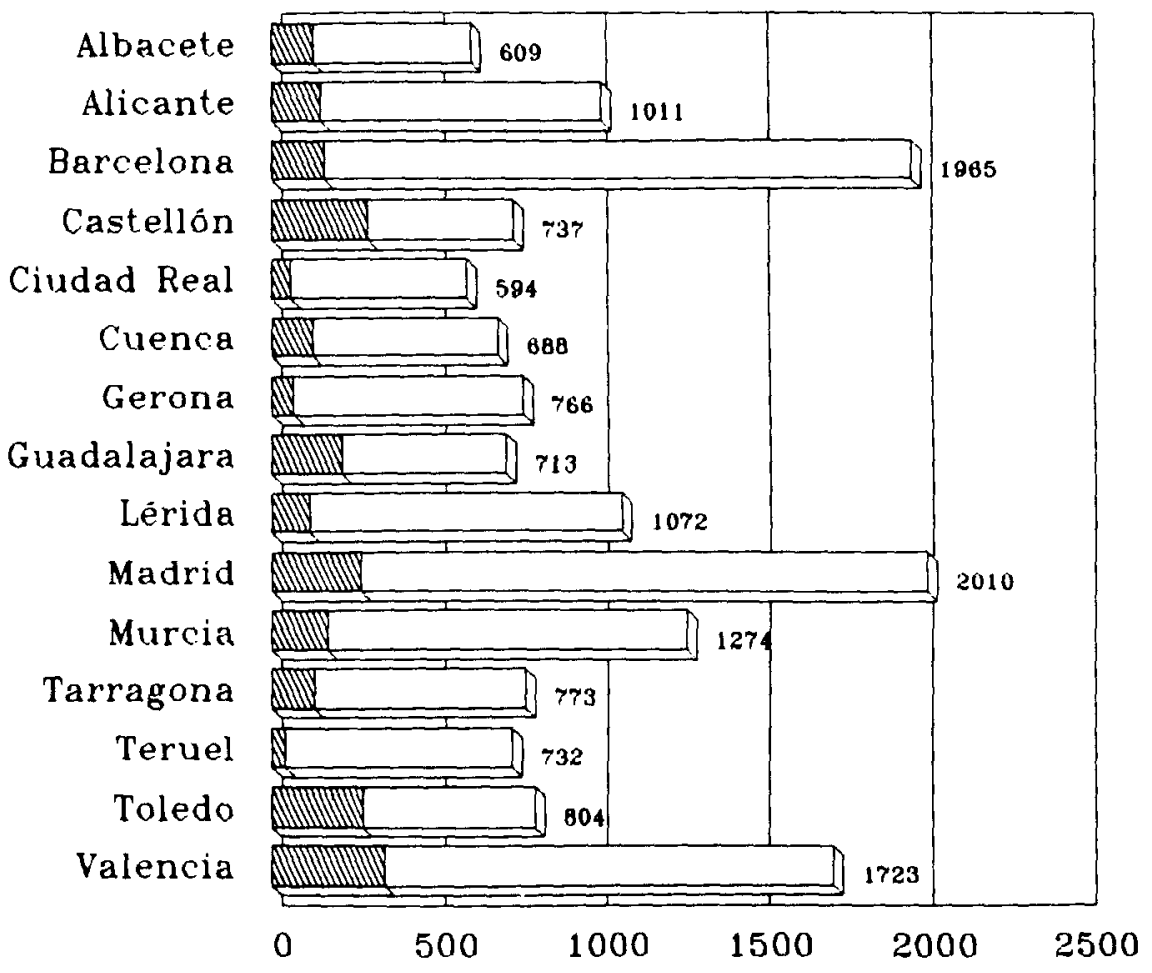

\section{Maestros}

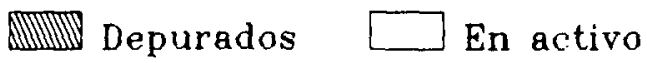

Rosalia Crego

Gráf. 6. 
En relación con "el profesorado de Universidad" es más difícil determinar el alcance de la depuración, si bien es altamente significativo que de 213 sancionados 148 sean catedráticos y sólo 65 otro personal docente entre profesores numerarios, auxiliares y otros cargos, cuando en todo caso siempre es muchisimo menor el número del Cuerpo de Catedráticos. Por otra parte, en las Universidades que estaban localizadas en la zona Nacional no se depuró al profesorado a no ser aquellas personas, que como Gil Robles, era líder político de las derechas y por ello fue inmediatamente depurado. Este acto tuvo sólo carácter simbólico.

Veamos que ocurrió en la Universidad de Madrid y sacaremos las consecuencias pertinentes.

Los profesores totales de las Facultades de Ciencias, Derecho, Farmacia, Medicina, Filosofía y Letras .................. 224

El total de depurados $\ldots \ldots \ldots \ldots \ldots \ldots \ldots \ldots \ldots \ldots \ldots \ldots, \quad 50$

El porcentaje fue de un 22,32 \%.

Es importante considerar que de estos "50 sancionados, eran catedráticos 40\%. Está muy claro que la acción depuradora se ejerció fundamentalmente hacia los docentes de élite como afirmamos anteriormente.

En la Universidad de Valencia había 81 profesores de los cuales se depuraron a 38. Las sanciones fueron las siguientes:

- Separación definitiva ......... 25 (catedráticos: 22)

- Jubilación forzosa ............. 5

- Disponibles gubernativo ....... 3

- Abandono de destino .......... 5

Total ........................... 38

Porcentaje ................... $46,9 \%$

También en esta Universidad el número de catedráticos (22) depurados fue muy elevado ${ }^{31}$.

En cuanto al profesorado de Segunda Enseñanza se repite el mismo esquema, fueron muchos más, proporcionalmente, los catedráticos depurados que el resto de los profesores de Institutos nacionales. Es difícil hacer una estadística rigurosa sobre este colectivo docente por la gran variedad de puestos: Profesores numerarios, auxiliares, encargados de

${ }^{31}$ Estos datos tomados del libro de M. ${ }^{a}$ Fernanda Mancebo: La universidad de Valencia en guerra. La FUE (1936-1939). Universitat de Valencia, 1988, pág. 73, coinciden con los datos recogidos por mi a partir de la $G R$ 
Depuración del personal docente en la zona republicana durante ...

curso, etc. Tampoco está muy claro si son IB nacionales, locales, elementales, etc.

Como la sanción se realiza por puestos de trabajo en las diferentes provincias, pero se desconoce cómo estaban compuestos los Institutos en cuanto al número de catedráticos o profesores había en cada uno. Los resultados son indicativos, en ningún momento exactos, como sí ocurre con otros docentes como maestros o inspectores por ejemplo. Considerando que había 2.302 profesores de IB distribuidos en 93 Institutos nacionales, puede considerarse que en cada instituto habría aproximadamente: 24 profesores, catedráticos incluidos. Aplicado este número a las provincias que elegimos como muestra veamos lo que ocurre:

\section{PROFESORES DEPURADOS POR PROVINCIAS}

\begin{tabular}{|c|c|}
\hline Albacete & 2 profesores. \\
\hline Alicante & - \\
\hline Barcelona & 27 (6 catedráticos, 21 profesores). \\
\hline Castellón & - \\
\hline Ciudad Real & 12 ( 3 catedráticos, 9 profesores). \\
\hline Cuenca $\ldots . . . . . . . . . . . . .$. & 1 Profesor Auxiliar. \\
\hline Gerona & 7 ( 3 catedráticos, 9 profesores). \\
\hline Guadalajara & 3 catedráticos. \\
\hline Lérida & 5 catedráticos. \\
\hline Madrid & 37 (19 catedráticos, 18 profesores). \\
\hline Murcia & 6 (2 catedráticos, 4 profesores). \\
\hline Tarragona & 5 (3 catedráticos, 2 profesores). \\
\hline Teruel .... & - \\
\hline Toledo & - \\
\hline Valencia ........... & 5 (4 catedráticos, 1 profesor). \\
\hline Total & 116 \\
\hline
\end{tabular}

Núm. Aprox. de profesores: 480.

Porcentaje: $24,16 \%$.

En el último gráfico, observaremos, que los espacios de las barras en blanco, corresponden a los docentes no maestros. En este sentido son Barcelona, Madrid y Valencia las que tienen más espacio y ello porque se depuraron gran número de catedráticos y profesores de Universidad e Institutos. 


\section{DEPURADOS POR PROVINCIA}

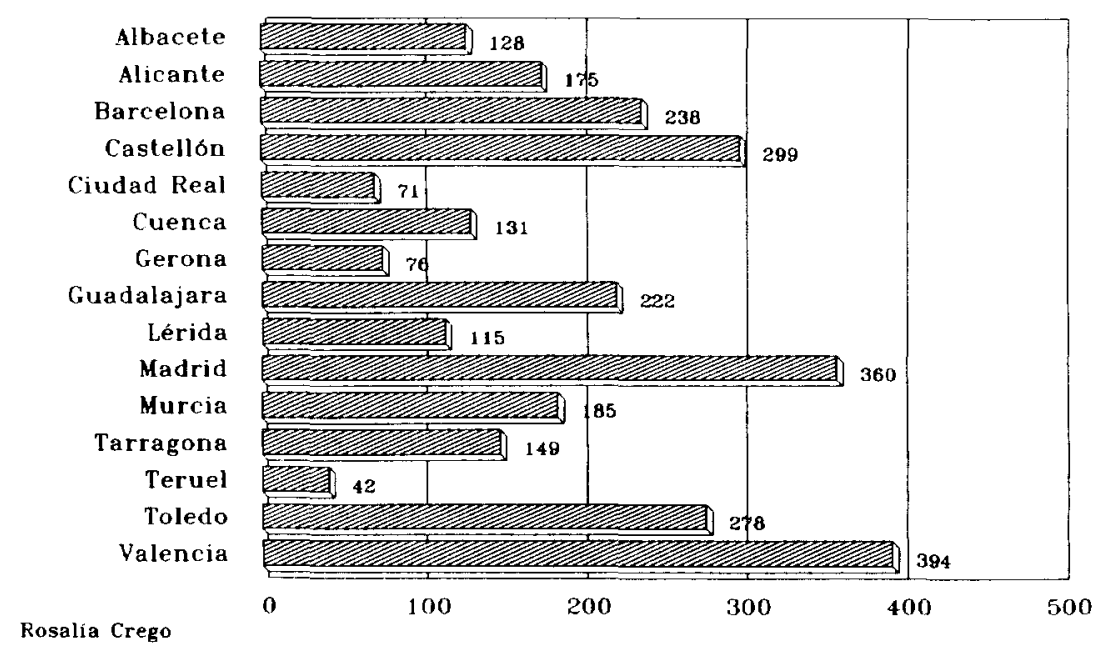

Gráf. 7.

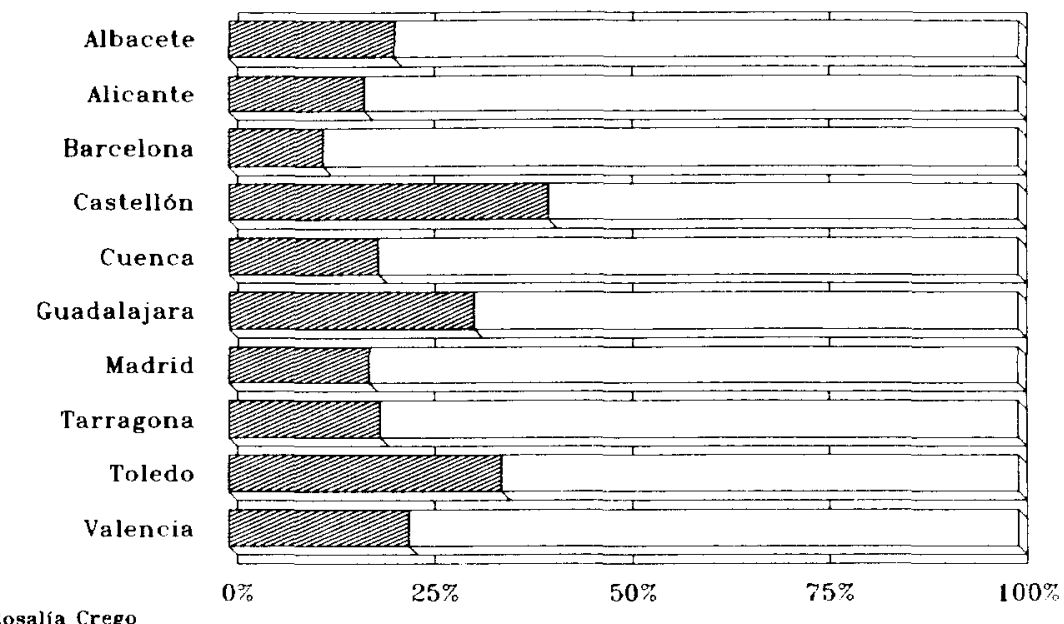

Gráf. 8. 
Depuración del personal docente en la zona republicana durante ...
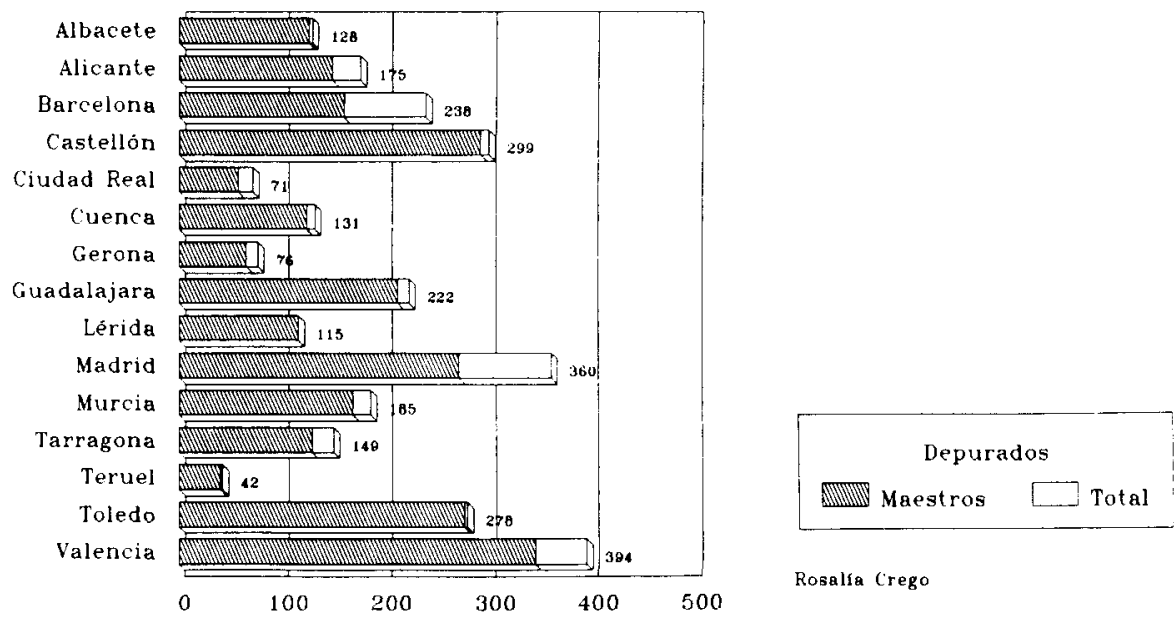

Rosalía Crego

Gráf. 9.

\section{CONSECUENCIAS DE LA DEPURACIÓN}

Aparte de los perjuicios personales de carácter económico, moral o profesional que cualquier tipo de sanción debió suponer, hubo otras consecuencias negativas de tipo general que conviene considerar.

La primera de ellas y la más importante fue el déficit de maestros que se ocasionó con tales medidas. La escasez de maestros producida por la incorporación a filas se aumentó con el abandono de escuelas, el cese, el traslado forzoso y demás sanciones o actos represivos. Este déficit va a hacer imposible que se llevara a cabo una enseñanza normalizada y mucho menos innovadora.

El Ministerio que había ocasionado, en cierta medida, este problema trató de resolverlo organizando cursos intensivos de corta duración en las Escuelas Normales, dando escuelas a "cursillistas" sin las debidas garantías de formación, por la propia brevedad de tal formación y colocando a los maestros alumnos e incluso nombrando como maestros a personas 
con alguna cultura pero sin titulación y con una preparación pedagógica dudosa cuando menos ${ }^{32}$.

Existe abundante documentación que apoya el reconocimiento que sobre dicho problema tuvieron las autoridades ministeriales. En un artículo de la revista Magisterio Español firmado por Pedro Lópiz Llópis, inspector central, se lamenta de la gran cantidad de escuelas cerradas a causa de la marcha de maestros al frente y a causa de la fuerte depuración que "ha sido necesario hacer" ${ }^{33}$.

Otra consecuencia fue la promoción rápida que consiguieron aquellos profesionales de la enseñanza, en general muy jóvenes, que por su actividad sindical o política dentro de los partidos o sindicatos de la izquierda en especial de FETE. Es fácil echar una ojeada a la Gaceta de la República en los primeros meses de la guerra y en los cambios ministeriales, para comprobar los nombramientos de tales beneficiados, sin que esté muy claro si su preparación correspondía a su puesto. De todos los profesionales quizá los más promocionados fueron los maestros que ocuparon puestos de inspectores, directores provinciales o destacados cargos políticos, ya que fueron maestros: directores generales y subsecretarios de los dos últimos Gabinetes Ministeriales. Tal vez ello estuvo motivado por la actitud de apoyo de este colectivo a la causa republicana y fue por tanto un reconocimiento de su actuación generosa y esforzada durante la guerra ${ }^{34}$.

La explicación a tal actitud de los maestros, así como a la consideración que el bando enemigo tuvo del maestro al que calificó generalizadamente de "rojo", estuvo sin duda motivada por el agradecimiento que el Magisterio debia al Gobierno de la República que hizo un gran esfuerzo por dignificar la función docente y mejorar la condición económica de aquellos, aunque no se consiguiera en la medida adecuada. Lo cierto fue

${ }^{32}$ En la GR, núm. 790 , de 20-3-1937, se reconoce por parte de la propia DG de Primera Enseñanza como: clas necesidades de la guerra han originado en ciertas regiones (en especial Aragón y Lérida) la escasez de personal docente primario y como consecuencia un número considerable de escuelas no pueden funcionar". En otra ocasión y en circular de la DG de Primera Enseñanza de fecha 23-6-1938 se reconoció igualmente que "la necesidad apremiante de formar con la mayor rapidez posible a los maestros que se necesitaban, provocó una rapidísima formación que forzosamente habia de redundar en perjuicio de la capacidad profesional del futuro maestro...".

${ }^{33}$ Magisterio Español. Valencia, 14/17-4-1937: "Déficit de Maestros". Se insiste de nuevo en el tema en la citada revista el 23-6-1937.

${ }^{34}$ Apoyan dicha afirmación los numerosos nombramientos de maestros como inspectores interinos, directores provinciales y diferentes cargos ministeriales importantes en la Gaceta de la República. 
que hubo numerosos maestros voluntarios en distintos batallones del quinto regimiento y alguno de ellos como Félix Bárzana llevó el nombre del primer maestro caido heroicamente en la defensa de Madrid ${ }^{35}$. Muchos fueron los maestros reconocidos como "héroes" de la República porque fueron muchos los que cayeron en la lucha. Sobre este hecho se recogen en un emotivo poema de $M$. Alonso Calvo titulado «Han matado al maestro" publicado en el Mono Azul las siguientes expresiones:

\author{
«... Han cerrado las escuelas \\ para dar placer al fuego \\ muchos niños de Castilla \\ se han quedado $\sin$ maestro ${ }^{36}$.
}

Aquellos maestros mutilados o heridos de guerra tuvieron preferencia a la hora de salir de España con colonias de niños.

Otra consecuencia indirecta de la depuración fue la obligatoriedad con que se impuso la sindicación del personal docente para evitar sanciones o males mayores. El sindicato que más se benefició fue FETE que llegó incluso a hacerse cargo de las habilitaciones. En este sentido se ordenó durante el período en que estuvo al frente del Gabinete de Instrucción Pública, Jesús Hernández, que los sindicatos que tuvieran mayor número de afiliados se encargaran de pagar el sueldo a los maestros. Evidentemente la mejor forma de no tener problemas a la hora de cobrar el escaso sueldo era hacerse de dicho sindicato. También al Sindicato de Profesiones Liberales de CNT acudieron muchos maestros especialmente los catalanes, pero en ambos casos, su pertenencia no fue libremente elegida, sino provocada por la necesidad de poseer un carnet que les protegiera ${ }^{37}$.

El resumen final del hecho histórico de la depuración no es con todo tan negativo como pudiera pensarse porque perdida la guerra por el Gobierno republicano la misma sanción fue alegada por los interesados a manera de aval o mérito para obtener una promoción profesional, aunque

${ }^{35}$ Magisterio Español, de fecha 22-8-1936: "Héroes de la República. Más compañeros muertos".

${ }^{36}$ Mono Azul, núm. 11. Año I, de 5-11-1936: "Han matado al maestro", pág. 85.

${ }^{37}$ Documentación de los maestros Esparza, que habian estado al cargo de unas colonias de niños cerca de Burdeos y piden su ingreso al Ministerio de Educación del Gobierno de Franco, "año de la Victoria". Explican (posiblemente con exageración) que su pertenencia a FETE, fue obligada. AGA. Caja 17.098. 
no faltara quien excepcionalmente fuera doblemente depurado, como aquellos exiliados, que no podian regresar con el régimen de Franco y por otra parte el propio Ministerio de IP del Gobierno del Frente Popular durante la guerra desaprobara su comportamiento o les sancionara. 